\title{
PENERAPAN STRATEGI MARKETING 4.0 PADA WISATA MUSEUM SEPULUH NOVEMBER (TUGU PAHLAWAN) SURABAYA
}

\author{
Citra Anggraini Tresyanto ${ }^{1}$ \\ Stephanie Astrid $\mathrm{Ayu}^{2}$ \\ Fakultas Ekonomi Universitas Katolik Darma Cendika, Surabaya, \\ Indonesia ${ }^{1,2}$ \\ E-mail : citra.anggraini@ukdc.ac.id
}

\begin{abstract}
The Ten November Museum which depicts the struggle of the Suroboyo arek during the struggle era, this is the reason why the number of community visits to the November 10 Museum is very small. With the sophistication of technology, this should not be an obstacle to keep on informing the existence of the November 10 Museum, even more so among today's youth, whose world is very close to the development of Information Technology. The purpose of this research is to be more aggressive in introducing the existence of the Tugu Pahlawan museum by applying Marketing Strategy 4.0 which focuses on the application of 5 A (Aware, Appeal, Ask, Act, Advocate). This study uses a qualitative approach with descriptive analytic methods. Data collection techniques in this research are field studies and literature studies. The primary data of this study were from observations and interviews with the public and museum officials as well as other informants needed to obtain a more complete picture, while the secondary data of this study were processed data from museum officials. The results of this study improve visiting the need for information on the existence of the museum, provide an interesting program, officers must be able to answer questions well and easily understood by visitors, the public is given appropriate information and promote the museum through social media.
\end{abstract}

Keywords: Tourism; Museum; Marketing Strategy; Social Media.

\begin{abstract}
ABSTRAK
Paradigma sebagian masyarakat yang menganggap bahwa museum kurang baik, salah satu faktor masyarakat kurang berminat berkunjung ke museum Sepuluh Nopember. Seharusnya dengan adanya kecanggihan teknologi, hal ini bukan menjadi penghalang untuk terus menginformasikan keberadaan Museum Sepuluh November, terlebih lagi di kalangan remaja masa kini, yang mana dunianya sudah sangat dekat dengan perkembangan Teknologi Informasi. Tujuan dari penelitian ini adalah lebih agresif lagi memperkenalkan keberadaan museum Tugu Pahlawan dengan menerapkan Strategi Marketing 4.0 yang berfokus pada penerapan 5A (Aware, Appeal, Ask, Act, Advocate). Penelitian ini menggunakan pendekatan kualitatif dengan metode deskriptif analitik. Teknik pengumpulan data dalam penelitian ini adalah studi lapangan dan studi kepustakaan. Data primer penelitian ini dari pengamatan dan wawancara kepada masyarakat dan petugas museum serta informan lain yang diperlukan untuk memperoleh gambaran lebih lengkap, sedangkan data sekunder penelitian ini olahan data dari petugas museum. Hasil penelitian ini meningkatkan kungjungan perlu informasi keberadaan museum, memberi program yang menarik, petugas harus mampu menjawab pertanyaan baik dan mudah dipahami pengunjung, masyarakat diberi informasi yang sesuai dan mempromosikan museum melalui sosial media.
\end{abstract}

Kata kunci : Wisata; Museum; Strategi Marketing; Sosial Media. 


\section{PENDAHULUAN}

Keberadaaan Museum merupakan salah satu tempat yang juga mampu menyuguhkan perasaan-perasaan yang menyenangkan. Melalui adanya wisata edukasi dan sejarah, museum menjadi bagian yang cukup penting. Melalui kunjungan museum, masyarakat terutama generasi muda dapat mengambil pembelajaran dan pengalaman dari peristiwa terdahulu. Pandangan sebagian masyarakat bahwa museum kurang baik merupakan salah satu penyebab museum bukan tujuan utama dalam berwisata. Jika ditelusuri lebih dalam lagi, banyak masyarakat yang tidak mengetahui keberadaan dari museum serta tidak pula memahami manfaat yang akan didapat dalam mengunjungi museum.

Maka permasalahan utama dalam hal ini adalah minimnya informasi tentang museum, membuat sebagian besar masyarakat tidak terpikirkan untuk mengunjunginya atau merekomendasikan orang lain untuk mengunjungi. Museum Sepuluh November misalnya, sebagian besar masyarakat menganggap bahwa Tugu Pahlawan hanya merupakan sebuah monument yang mengingatkan perjuangan arek-arek Suroboyo pada jaman perjuangan dulu. Padahal nyatanya lokasi monument Tugu Pahlawan juga memiliki museum yang lebih jauh memberikan gambaran peristiwa dan beberapa benda sejarah yang menjadi saksi bisu perjuangan kemerdekaan. Melalui wisata museum Sepuluh November (Tugu Pahlawan), masyarakat akan jauh lebih memaknai kehidupan setelah kemerdekaan ini dengan lebih baik. 
Harus diakui memang keberadaan Museum Sepuluh November (Tugu Pahlawan) luput dari perhatian warga kota Surabaya dan wisatawan, meski sesungguhnya museum tersebut memiliki potensi yang sangat besar. Diperlukan strategi awal yang perlu dilakukan adalah penyampaian informasi terkait keberadaan museum tersebut. Melalui penetapan strategi Marketing 4.0, akan sangat memungkinkan hal tersebut terwujud. Dengan pemanfaatan kecanggihan teknologi yang ada, maka akan memudahkan penyampaian informasi keberadaan museum kepada masyarakat. Saat ini perkembangan teknologi sudah berbasis online, strategi Marketing 4.0 tetap juga mengedepankan strategi marketing secara offline.

Strategi marketing yang akan ditetapkan adalah dua sisi yaitu online dan offline. Hal ini bertujuan agar dapat menjangkau semua kalangan masyarakat. Meskipun strategi online sudah sangat mampu menjangkau ke lebih banyak orang namun nyatanya strategi offline juga masih sangat dibutuhkan oleh masyarakat. Karena melalui strategi offline, masyarakat secara nyata akan merasakan keberadaan museum Sepuluh November (Tugu Pahlawan) sebagai salah satu tempat destinasi hiburan yang bernilai edukasi.

Penelitian ini menjadi begitu penting bagi kelangsungan keberadaan museum dan pengetahuan jejak sejarah kota Surabaya khususnya. Tugu Pahlawan adalah icon kota Surabaya yang di dalamnya juga terdapat museum yang menggambarkan dengan detail perjuangan arek-arek Suroboyo dalam merebut kemerdekaan kala itu. Dukungan masyarakat untuk kelangsungan keberadaan 
museum sanagt dibutuhkan, tidak hanya sekedar dukungan dalam bentuk kunjungan namun juga ikut ambil bagian dalam keberlanjutan museum seperti dalam bentuk dukungan moril dan materiil juga dapat dilakukan.

Museum Pendidikan dan Mainan Anak Kolong Tangga Yogyakarta, yang telah berdiri sejak tahun 2008 terpaksa ditutup pada Juli 2017 lalu. Penutupan ini dikarenakan tempat yang selama ini ditempati akan dilakukan alih fungsi, namun sayangnya sampai dengan detik ini tidak ada tempat pengganti untuk memamerkan ribuan koleksi yang dimiliki. Penutupan museum juga terjadi pada Museum Sejarah Bentoel di Wirimargo kota Malang. Museum tersebut berisi koleksi yang menceritakan perkembangan industri rokok Bentoel yang didirikan oleh Ong Hok Liong sejak awal tahun 1900-an. Penutupan ini dilakukan sejak Agustus 2019 dikarenakan pemilik asetnya mempunyai keinginan untuk menjual gedung museum tersebut dan memindahkan semua koleksinya ke tempat lain.

Sangat disayangkan bila gedung museum tersebut menjadi bagian tak terpisahkan dari country heritagekota Malang. Sungguh tidak dapat dibayangkan apabila penutupan museum juga terjadi di Kota Surabaya. Tercatat 22 museum dimiliki oleh Kota Surabaya, termasuk di dalamnya yang menjadi icon Kota Surabaya adalah Museum Sepuluh November (Tugu Pahlawan). Maka penelitian ini juga berarti menjaga kekayaan intelektual yang dimiliki bangsa Indonesia melalui kekayaan sejarah dan pengetahuan melalui keberadaan museum.

Pengertian museum menurut Internasional Council of Museum (dalam Akbar, A), adalah: museum merupakan lembaga non profit yang memiliki sifat 
permanen yang melayani masyarakat dan perkembangan yang terjadi di lingkungan masyarakat, terbuka untuk umum, serta memiliki tugas mengumpulkan, melestarikan, meneliti, mengkomunikasikan, dan memamerkan warisan sejarah kemanusiaan yang berwujud benda dan non benda, bagi tujuan pendidikan, penelitian, dan hiburan.

Berdasarkan hasil musyawarah umum ke-11 (11 $1^{\text {th }}$ General Assembley) International Council of Museum (ICOM) pada tanggal 14 Juni 1974 di Denmark (dalam Akbar, Ali), terdapat sembilan fungsi dari museum itu sendiri, yaitu: 1). Pengumpulan dan pengamanan warisan alam dan budaya. 2). Dokumentasi dan penelitian ilmiah. 3). Konservasi dan preservasi. 4). Penyebaran ilmu. 5). Pengenalan dan penghayatan kesenian. 6). Pengenalan kebudayaan. 7). Visualisasi warisan alam dan budaya. 8). Cermin pertumbuhan peradaban manusia. 9). Pembangkit rasa bertakwa dan bersyukur kepada Tuhan Yang Maha Esa.

Menurut American Marketing Association (Tjiptono \& Diana, 2016) pemasaran sendiri merupakan aktivitas, rangkaian institusi, dan proses menciptakan, mengkomunikasikan, menyampaikan, serta saling menukarkan penawaran (offerings) yang bernilai bagi pelanggan, klien, mitra, dan masyarakat umum.

Agar dapat memenangkan advokasi pada konsumen diperlukan strategi marketing 4,0. Menurut Philip Kottler (dalam Krisnawati, 2018) bahwa teori pemasaran 4.0 atau pemasaran digital dengan pendekatan pemasaran baru untuk membantu pemasar dalam mengatisipasi dan mengelola dampak teknologi. Konsep 
tersebut mengkombinasikan interaksi online dan interaksi offline antara perusahaan dengan pelanggan karena pada kenyataannya, justru di saat dunia online berkembang, sentuhan offline menjadi titik diferensiasi yang kuat. Strategi marketing 4,0

Pada era industri 4.0 sebagian besar memanfaatkan kecanggihan teknologi yang ada namun menurut Marketing 4.0 interaksi secara offline tetap diperlukan. Hal ini dikarenakan untuk menarik konsumen sampai pada tindakan menganjurkan itu muncul, maka tetap dibutuhkan sentuhan dari produsen untuk menghasilkan pelayanan yang maksimal. Karena itu, konsep Marketing 4.0 sendiri tidak bertujuan untuk menjatuhkan marketing offline yang mungkin sudah terbentuk (Kartajaya, 2017).

Dalam penerapan marketing 4.0 dibutuhkan digital marketing yang baik agar tujuan daripada konsep marketing 4.0 dapat terwujud. Menurut Kartajaya (2019) konsep marketing 4.0 mengaplikasikan modifikasi dari Empat A (Aware, Attitude, Ask, Act Again)menjadi Lima A (Aware, Appeal, Ask, Act, Advocate). Pada tahap awal aware (menyadari) konsumen menghadapi daftar panjang merek dari pengalaman masa lalu, komunikasi pemasaran, dan/atau anjuran orang lain.

Iklan adalah bentuk informasi produk maupun jasa dari produsen kepada konsumen maupun penyampaian pesan dari sponsor melalui suatu media (Lukitaningsih, 2013). Cara yang efektif untuk menyebarkan pesan, baik untuk membangun preferensi merek atau untuk mendidik masyarakat adalah dengan iklan. Dengan menggunakan strategi pengiklanan produk yang tepat akan membuat 
konsumen menjadi lebih mengetahui dan memahami tentang produk yang diproduksi oleh suatu perusahaan Kotler dan Keller (2012: 526).

Dalam informasi yang tersampaikan pada konsumen tersebut tersimpan daya tarik tersendiri yang kemudian konsumen masuk pada tahapan appeal (daya tarik). Ketertarikan konsumen terhadap informasi merupakan factor yang penting yang akan mempengaruhi konsumen masuk pada tahap selanjutnya yaitu ask (bertanya). Tahapan bertanya konsumen saat ini dilakukan dengan perpaduan dunia digital (online) dan fisik (offline). Karena itu, perusahaan harus dalam saluran media yang popular sehingga mampu menjawab pertanyaan-pertanyaan konsumen. Jika dirasa konsumen yakin dan cukup puas terhadap informasi yang diterima, maka konsumen akan memutuskan untuk act (bertindak). Keterlibatan perusahaan dalam tahap ini adalah memastikan bahwa pelanggan mendapatkan apa yang diinginkan sesuai dengan hasil pencarian mereka saat berada di tahap bertanya. Maka setelah itu didapatkan, konsumen dengan antusias masuk pada tahap advocate (menganjurkan). Secara spontan dan tanpa diminta konsumen akan merekomendasikan melalui saluran social yang dimilikinya atau dengan tanpa beban menceritakan apa yang dirasakan setelah melewati semua tahapan.

\section{METODE PENELITIAN}

Penelitian ini menggunakan pendekatan kualitatif dengan metode deskriptif analitik. Teknik pengumpulan data dalam penelitian ini adalah studi lapangan dan studi kepustakaan. Dalam penelitian ini, data yang digunakan adalah data primer yang terdiri dari data yang diperoleh langsung dari pengelola museum, pengunjung, 
Dinas Pariwisata Kota Surabaya dan masyarakat melalui pengumpulan dan wawancara untuk memperoleh informasi mengenai pengembangan dan pengelolaan museum.

Penelitian ini menggunakan metode penelitian kualitatif dengan pendekatan dekriptif analitik. Creswell (dalam Herdiansyah, 2010: 8), bahwa penelitian kualitatif adalah proses penyelidikan pemahaman berdasarkan tradisi metodologi penyelidikan yang berbeda dengan mengeksplorasi masalah sosial atau manusia. Peneliti membangun gambaran yang kompleks dan holistik, menganalisis katakata, melaporkan pandangan terperinci informasi, dan melakukan penelitian dalam lingkungan alami. Sedangkan Meleong (dalam Herdiansyah, 2010: 9) bahwa penelitian kualitatif adalah suatu penelitian ilmiah, yang memiliki tujuan untuk memahami suatu fenomena dalam konteks sosial secara alamiah dengan mengedepankan proses interaksi komunikasi yang mendalam antara peneliti dengan fenomena yang diteliti termasuk di dalamnya bagian-bagian lain yang ikut mempengaruhi. Dalam melakukan proses analisis data, penelitian ini mengacu pada model analisis interaktif yang dikembangkan oleh Matthew B. Miles dan A. Michael Huberman (dalam Soegiyono, 2007).

Tahapan model analisis interaktif adalah sebagai berikut : 1). Pengumpulan Data adalah tahap mengumpulkan data yang diperoleh dari hasil wawancara, observasi, penelitian kepustakaan dan dokumentasi serta data sekunder lainnya. 2). Reduksi Data. Proses reduksi diartikan sebagai proses pemilihan, penyederhanaan, pengabstrakan dan pengubahan data yang belum terstruktur sebagai hasil dari 
catatan - catatan tertulis di lapangan. 3). Penyajian Data. Langkah berikutnya setelah reduksi data adalah penyajian data yang dimaknai sebagai sekumpulan informasi yang tersusun dengan kemungkinan adanya penarikan kesimpulan dan pengambilan tindakan. Dalam tahap ini dapat dipahami apa yang sedang terjadi dan apa yang harus dilakukan. 4). Penarikan Kesimpulan. Kegiatan analisis interaktif keempat adalah menarik kesimpulan dan melakukan verifikasi. Dari pengumpulan data sampai merujuk pada keteraturan pola yang ada dan menghasilkan satu kesimpulan akhir. Sedangkan verifikasi merupakan tinjauan ulang pada catatancatatan lapangan, dengan kata lain makna yang muncul dari data harus diuji kebenarannya (validitasnya), verifikasi dalam penelitian dilakukan secara kontinyu sepanjang penelitian sehingga terbentuk proposisi tertentu yang bisa mendukung teori ataupun penyempurnaan teori.

\section{HASIL DAN PEMBAHASAN}

Penelitian ini mengembangkan konsep marketing 4.0 Kartajaya (2019), yaitu : Aware, Attitude, Ask, Act Again dan Advocate). Setalah dilakukan penggalian data dilapangan diperoleh, banyaknya masyarakat Surabaya yang salah informasi mengenai keberadaan museum ini maka dibutuhkan adanya suatu strategi agar keberadaannya semakin dikenal oleh banyak masyarakat. Minimnya informasi mengenai museum tersebut juga menjadi salah satu alasan utama masyarakat tidak mengetahui keberadaan museum tersebut, sehingga masyarakat juga tidak tertarik untuk melalukan kunjungan. 
Dengan implementasi strategi marketing 4.0 untuk wisata datang ke Museum Sepuluh November, dengan komponen 5A (Aware, Appeal, Ask, Act, Advocate), diperoleh gambaran bahwa: 1). Aware. Tahap awal ini adalah tahap di mana konsumen menyadari untuk memiliki kegiatan berwisata namun belum menentukan tempat yang akan dituju. Untuk membangun kesadaran konsumen ini maka, Museum Sepuluh November (Tugu Pahlawan) dapat membuat layanan informasi yang baru dan lengkap agar dapat menarik konsumen. Layanan informasi yang dibuat dapat dengan memanfaatkan kecanggihan teknologi internet yang ada, melalui social media dan website. Semakin banyak orang mengetahui keberadaan Museum Tugu Pahlawan, maka akan semakin banyak masyarakat menyadari keberadaan Museum Tugu Pahlawan. 2). Appeal. Setelah konsumen menyadari keberadaan Museum Sepuluh November (Tugu Pahlawan), maka akan muncul ketertarikan dari masyarakat. Ketertarikan ini menjadi factor yang sangat penting karna langkah awal masyarakat memiliki keinginan untuk melakukan kunjungan ada pada tahap ini. Pada tahap ini dapat ditawarkan kegiatan atau program yang menarik di museum sehingga dapat lebih meyakinkan masyarakat untuk masuk pada tahap selanjutnya. 3). Ask. Ketertarikan yang lahir dari masyarakat tersebut akan memunculkan banyak pertanyaan seputar Museum Sepuluh November (Tugu Pahlawan). Pertanyaan yang kerap kali muncul seperti dimana lokasi pasti keberadaan museum, waktu operasional museum, koleksi apa saja yang bisa kita nikmati dan hal-hal apa yang bisa dipelajari di sana. Pertanyaan-pertanyaan tersebut baiknya dengan mudah didapat oleh masyarakat sehingga mereka yakin untuk melakukan kunjungan. 4). Act. Saat masyarakat menemukan semua jawaban dari 
pertanyaannya seputar keberadaan museum Sepuluh November (Tugu Pahlawan), maka masyarakat akan melakukan tindakan kunjungan. Pada tahap ini, baiknya Museum Sepuluh November (Tugu Pahlawan) memastikan semua informasi yang didapat oleh masyarakat sesuai dengan apa yang diterima pada saat berkunjung. Sehingga tidak timbul kekecewaan dari mereka. Penawaran lainnya yang menarik kunjungan berikutnya dapat ditawarkan seperti kegiatan-kegiatan yang diadakan di museum. 5). Advocate. Tahapan terakhir yang diharapkan setelah masyarakat melakukan kunjungan adalah mereka menganjurkan atau merekomendasikan komunitasnya untuk juga mengunjungi Museum Sepuluh November (Tugu Pahlawan). Hal ini juga bisa dilakukan dengan membuat program promosi melalui social media yang ada. Pengunjung yang sudah datang dapat mengikuti akun media social museum dan membagikan kunjungannya di sosial media.

Strategi marketing 4.0 sangat memanfaatkan adanya teknologi internet untuk memaksimalkan penyebaran informasi pada masyarakat secara lebih luas dan harus terus dilakukan banyak update. Tercatat dari hasil data yang didapatkan di lapangan, terdapat 1 situs blog internet, 1 akun Instagram dan 1 akun Facebook yang membahas keberadaan museum namun sudah cukup lama tidak dilakukan adanya pembaharuan data.

Dengan penggunaan sistem informasi fungsi marketing yang berkaitan dengan perencanaan, promosi dan penjualan serta pengembangan produkterfokus pada pelanggan yang didasarkan pada penggunaan teknologi internetakan terjadi transaksi dua arah antara organisasi dan pelanggan (Mochklas \& Setiawan, 2017). 
Maka perlu adanya kegiatan untuk pembaharuan data untuk media internet tersebut. Selain itu tidak melupakan kegiatan atau pelayanan tatap muka secara langsung. Karena kebutuhan interaksi secara langsung pada konsumen dalam hal ini pengunjung dirasa sangat dibutuhkan untuk terus menjaga loyalitas pengunjung. Penelitian selanjutnya yang dapat dikembangkan adalah strategi pengembangan event yang dapat dilakukan untuk membuat museum Sepuluh November lebih menarik dengan adanya event-event yang tiap bulan bias diadakan.

Dalam era industri 4.0 merupakan era baru, dimana industri ekonomi yang sangat jelas mempengaruhi segala aspek kehidupan manusia, dimana dengan penggunaan teknologi dapat meningkatkan penjualan (Mukarromah, et al., 2019). Kebutuhan dan keinginan masyarakat juga kerap kali berubah seiring dengan perubahan yang ada. Dalam dunia marketing, kondisi industri 4.0 ini jelas memiliki dampak yang sangat besar.

Tuntutan masyarakat juga semakin tinggi terhadap kebutuhan informasi produk atau perusahaan yang perlu mereka ketahui. Masyarakat saat ini sangat mengharapkan segala informasi yang dibutuhkan dapat segera mereka ketahui hanya dalam waktu yang singkat dan cara yang mudah. Termasuk juga dalam kegiatan kepariwisataan mereka. Tidak luput mengenai informasi keberadaan pariwisata museum yang dapat menjadi alternatif positif untuk kegiatan kepariwisataan mereka.

Strategi pemasaran sangat diperlukan (Firmansyah \& Mochklas, 2018) dalam meningkatkan daya tarik konsumen yang akan meningkatkan penjualan. Dari 
rangkaian informasi yang didapat dari masyarakat bahwasannya masyarakat tidak mengetahui keberadaan museum Sepuluh November yang masuk dalam satu kawasan Tugu Pahlawan. Tujuan awal kunjungan masyarakat di kawasan Tugu Pahlawan adalah menikmati suasana di sana, mengingat kawasan di Tugu Pahlawan sangat luas dan sejuk karna banyak tanaman yang menambah kerindangan suasana.

Beberapa mengetahui adanya museum di kawasan Tugu Pahlawan namun juga belum pernah melakukan kunjungan, dan sebagian besar masyarakat menganggap museum tersebut disebut pula dengan Museum Tugu Pahlawan. Nama sebenarnya yang belum banyak diketahui adalah Museum Sepuluh November. Kurangnya masyarakat memahami akan keberadaan museum, karena pihak pengelolah kurang dalam mempromosikan. Dengan bauran pemasaran dengan menggunakan teknologi akan memudah dalam promosi dengan biaya yang rendah (Rofi'i, at el., 2019).

Museum tersebut merupakan museum yang menggambarkan perjuangan arek-arek Suroboyo dalam melawan penjajahan pada jaman perjuangan kemerdekaan. Museum Sepuluh November terdiri dari 2 lantai, lantai 1 berisi ruang auditorium, perpustakaan, diorama dengan suara asli Bung Tomo sedangkan lantai 2 berisi diorama statis $1 \& 2$ (dilengkapi suara). Selain itu, Museum Sepuluh November juga memiliki koleksi replika bambu runcing, senjata-senjata perang, peninggalan perang, lukisan nuansa perang, foto gedung-gedung pada jaman penjajahan Belanda, piagam, dan lain sebagainya. Museum ini juga memiliki fasilitas lift dan escalatoryang dikhususkan bagi penyandang disabilitas. 


\section{SIMPULAN}

Dari hasil penelitian dan pembahasan penelitian ini daat disimpulkan bahwa: 1). Sebagai sarana wisata dan pendidikan pengelolah Meseum Tugu Pahlawan untuk membuat masyarakat yang ingin berwisata aware terhadap Meseum Tugu Pahlawan, perlu melakukan promosi. 2). Strategi promosi yang menarik (Appeal) akan membuat masyarakat Surabaya mengetahui Museum Sepuluh November (Tugu Pahlawan) sehingga masyarakat mantap untuk berkunjung. Dengan memanfaatkan teknologi informasi dan sosial media lebih memaksimalkan penyebaran informasi pada masyarakat secara lebih luas. 3). Didalam promosi juga harus memuat konten informasi sebagai jawaban pertanyaan masyarakat yang sering muncul, yaitu lokasi museum, waktu operasional museum, koleksi yang bisa di nikmati dan hal-hal apa yang bisa dipelajari di museum. Pemberian informasi harus terus di update. 4). Dengan strategi Act, diharapkan pengelolah Museum Sepuluh November (Tugu Pahlawan) yaitu dengan memberikan pelayanan yang baik dan informasi yang menarik serta menjawab pertanyaan pengunjung. 5). Pengelolah museum harus mampu membuat pengunjung sebagai advocate museum, yaitu dengan membuat acara, pelayanan yang membuat pengunjung berkesan sehingga dapat merekomendasikan kepada komunitasnya. Dan membuat pengunjung sebagai mitra yaitu dengan mengikuti akun media sosial museum dan membagikan kunjungannya di sosial media sebagai bentuk ucapan terimakasih. 


\section{REFERENSI}

Akbar, A. 2010. Museum di Indonesia: Kendala dan Harapan. Sinar Sintani: Jakarta

Direktorat Museum. 2009. Himpunan Peraturan Perundang-Undangan Republik Indonesia Tentang Museum, Direktorat Museum. Jakarta.

Direktorat Museum, Direktorat Jendral Sejarah dan Purbakala, Departemen Kebudayaan dan Pariwisata. Jakarta.

Direktorat Museum. 2008. Pedoman Museum Indonesia,

Direktorat Museum. 2009. Ayo Kita Mengenal Museum

Fatihudin, D., \& M. Mochklas. (2017). Analysis Of Factors Affecting Consumer Decisions Buy Motorcycle (Study On City Of Surabaya Indonesia). International Journal Of Innovative Research \& Development, 6(6), 107-118

Firmansyah, M.A. \& M. Mochklas. 2018. Analisa Strategi Produk, Harga, Promosi Dan Tempat Terhadap Kepuasan Pelanggan Warung Giras Di Surabaya. Jurnal Eksekutif, 15 (1):281-295

Herdiansyah, H. 2010. Metodologi Penelitian Kualitatif untuk Ilmu-Ilmu Sosial. Salemba Humanika: Jakarta

Hermawan, A. 2012. Komunikasi Pemasaran. Erlangga: Jakarta,

Kartajaya, H. dan Setiawan, I. 2017. Marketing 4.0. Gramedia: Jakarta.

Kotler, P., \& K. L. Keller. 2012. Marketing Management, 13 Edition. New Jersey: Pearson Education, Inc.

Krisnawati, D. 2018. Peran Perkembangan Teknologi Digital Pada Strategi Pemasaran Dan Jalur Distribusi UMKM Di Indonesia (Studi Kasus: UMKM Kuliner Tanpa Restaurant 'Kepiting Nyinyir'). Jurnal Manajemen Bisnis Krisnadwipayana, 6 (1):69-74

Lukitaningsih, A. 2013. Iklan Yang Efektif Sebagai Strategi Komunikasi Pemasaran. Jurnal Ekonomi dan Kewirausahaa, 13(2):116 - 129

Mochklas, M., \& T. Setiawan. 2018. Sistem Informasi Manajemen. Surabaya: TS Publisher.

Mukarromah, S., S. Maro'ah \& M. Mochklas. 2018. Implementasi Strategi Bauran Pemasaran Dalam Meningkatkan Volume Penjualan Toko Baju Senam Grosir.Com. Jurnal Eksekutif, 15(2), 316-333 
Pranata, I.W.D.R. \& Km. A.S. Pramudana. 2018. Peran Kesadaran Merek (Brand Awareness) Dalam Memediasi Hubungan Iklan Oppo Dengan Niat Beli Konsumen, E-Jurnal Manajemen Unud, 7(10): 5230-5257

Rofi'i, N.A., D. Fatihudin \& M. Mochklas. 2019. Pengaruh Strategi Bauran Pemasaran Terhadap Peningkatan Penjualan Pada Produk Dr. Kebab Bara Satriya Sidoarjo. Balance, 16(1):112-119

Soegiyono, M. 2007. Metodelogi Penelitian Kuantitatif, Kualitatif, R\&D. CV. Alfabeta: Bandung

Tjiptono, F., \& A. Diana. 2016. Pemasaran: Esensi dan Aplikasi. Andi Offset: Yogyakarta.

Tjiptono, F., \& G. Chandra. 2012. Service, Quality \& Satisfaction Edisi 3. Andi Publisher: Jakarta. 